\title{
IL-15 induces CD4+ effector memory T cell production and tissue emigration in nonhuman primates
}

\author{
Louis J. Picker, ${ }^{1}$ Edward F. Reed-Inderbitzin, ${ }^{1}$ Shoko I. Hagen, ${ }^{1}$ John B. Edgar, ${ }^{1}$ Scott G. Hansen, ${ }^{1}$ \\ Alfred Legasse, ${ }^{1}$ Shannon Planer, ${ }^{1}$ Michael Piatak Jr., ${ }^{2}$ Jeffrey D. Lifson, ${ }^{2}$ Vernon C. Maino, ${ }^{3}$ \\ Michael K. Axthelm, ${ }^{1}$ and Francois Villinger ${ }^{4}$
}

\Vaccine and Gene Therapy Institute, Departments of Pathology and Molecular Microbiology and Immunology, and Oregon National Primate Research Center Oregon Health \& Science University, Beaverton, Oregon, USA. 2AIDS Vaccine Program, SAIC-Frederick Inc., National Cancer Institute at Frederick, Frederick, Maryland, USA. ${ }^{3}$ BD Biosciences, San Jose, California, USA. ${ }^{4}$ Department of Pathology and Laboratory Medicine, Emory University, Atlanta, Georgia, USA.

\begin{abstract}
HIV infection selectively targets $\mathrm{CD}^{+}$effector memory $\mathrm{T}\left(\mathrm{T}_{\mathrm{EM}}\right)$ cells, resulting in dramatic depletion of $\mathrm{CD} 4^{+} \mathrm{T}$ cells in mucosal effector sites in early infection. Regeneration of the $T_{E M}$ cell compartment is slow and incomplete, even when viral replication is controlled by antiretroviral therapy (ART). Here, we demonstrate that IL-15 dramatically increases in vivo proliferation of rhesus macaque (RM) $\mathrm{CD}^{+}$and $\mathrm{CD8}^{+} \mathrm{T}_{\mathrm{EM}}$ cells with little effect on the naive or central memory $\mathrm{T}\left(\mathrm{T}_{\mathrm{CM}}\right)$ cell subsets, a response pattern that is quite distinct from that of either IL-2 or IL-7. $T_{E M}$ cells produced in response to IL-15 did not accumulate in blood. Rather, 5-bromo-2'-deoxyuridine (BrdU) labeling studies suggest that many of these cells rapidly disperse to extralymphoid effector sites, where they manifest (slow) decay kinetics indistinguishable from that of untreated controls. In RMs with uncontrolled SIV infection and highly activated immune systems, IL-15 did not significantly increase CD4 ${ }^{+} T_{\mathrm{EM}}$ cell proliferation, but with virologic control and concomitant reduction in immune activation by ART, IL-15 responsiveness was again observed. These data suggest that therapeutic use of IL-15 in the setting of ART might facilitate specific restoration of the $\mathrm{CD}^{+} \mathrm{T}$ cell compartment that is the primary target of $\mathrm{HIV}$ with less risk of exhausting precursor $\mathrm{T}$ cell compartments or generating potentially deleterious regulatory subsets.
\end{abstract}

\section{Introduction}

Infection-transmitting HIV and its nonhuman primate (NHP) counterpart SIV use CCR5 as their primary coreceptor and therefore preferentially target the differentiated CD4+ "effector memory" $\mathrm{T}\left(\mathrm{T}_{\mathrm{EM}}\right)$ cells that constitute the major population of $\mathrm{CD}^{+} \mathrm{T}$ cells in extralymphoid effector sites such as the intestinal lamina propria, lung, and vaginal mucosa (1-4). This targeting results in the massive depletion of these populations during acute infection (5-10). Regeneration is inefficient, and mucosal $\mathrm{CD}^{+} \mathrm{T}$ cell deficits persist indefinitely in most infected individuals $(5-7,11)$, even with effective antiretroviral therapy (ART) $(6,12-14)$. Restoration of depleted $\mathrm{CD}^{+} \mathrm{T}$ cell populations has long been a therapeutic goal in HIV infection, but the recent realization that the $\mathrm{T}_{\mathrm{EM}}$ cell compartment bears the brunt of viral attack and is most closely linked with defense against opportunistic pathogens (7) suggests that these restoration efforts should include, if not focus on, this compartment.

$\mathrm{T}_{\mathrm{EM}}$ cells, both $\mathrm{CD}^{+}$and $\mathrm{CD}^{+}$, represent functionally differentiated cell types that are derived from antigen-stimulated naive precursors in the primary response or from central memory $\mathrm{T}$ $\left(\mathrm{T}_{\mathrm{CM}}\right)$ cell precursors at later time points (4). Although mechanisms influencing the functional specialization of differentiating $\mathrm{T}_{\mathrm{EM}}$ cells have been described (4), their in vivo population dynamics, including the factors regulating the extent of their recruitment

Nonstandard abbreviations used: ART, antiretroviral therapy; BAL, bronchoalveolar lavage; BrdU, 5-bromo-2'-deoxyuridine; FTC, $\beta$-2' $3^{\prime}$-dideoxy- $3^{\prime}$-thia-5-fluorocytidine; NHP, nonhuman primate; PMPA, 9-R-(2-phosphonomethoxypropyl)adenine; RhCMV, rhesus cytomegalovirus; $\mathrm{RM}$, rhesus macaque; $\mathrm{T}_{\mathrm{CM}}$, central memory $\mathrm{T}$ (cell); $\mathrm{T}_{\mathrm{EM}}$, effector memory $\mathrm{T}$ (cell).

Conflict of interest: The authors have declared that no conflict of interest exists. Citation for this article: J. Clin. Invest. 116:1514-1524 (2006). doi:10.1172/JCI27564. from less differentiated precursors, their proliferative/self-renewal capacity, and their lifespan, are poorly characterized, particularly for the $\mathrm{CD}^{+}$lineage. Previous work has implicated the common $\gamma$ chain family cytokines IL-2, IL-7, and IL-15 as important general regulators of peripheral $\mathrm{T}$ cell homeostasis (15-19). IL-2, a product of activated T cells, supports expansion of antigen-activated $\mathrm{CD}^{+}$and $\mathrm{CD}^{+} \mathrm{T}$ cells, but its primary, nonredundant role in immune regulation appears to be the production of regulatory $\mathrm{T}$ cells and maintenance of peripheral tolerance (20). IL-7 is produced by nonlymphoid cells and plays a crucial role in promoting expansion of both thymic and peripheral $\mathrm{T}$ cell populations, the latter including both the $\mathrm{CD}^{+}$and $\mathrm{CD}^{+}$lineages, and both the naive and memory compartments $(15,21-23)$. IL-15, also produced by nonlymphoid cell types, directs NK cell and NK-T cell development, as well as $\mathrm{CD}^{+}$memory $\mathrm{T}$ cell function and homeostasis $(15,17,18,23-25)$. Significantly, while rodent studies have clearly demonstrated a major role for IL-15 in the regulation of both homeostatic and infection-associated $\mathrm{CD} 8^{+}$memory $\mathrm{T}$ cell proliferation, most studies have not shown analogous activity in the $\mathrm{CD}^{+}$memory compartment $(15,26-28)$.

In SIV-infected NHPs, provision of exogenous IL-15 has been demonstrated to increase the numbers of circulating $\mathrm{CD}^{+} \mathrm{T}$ cells, preferentially affecting the $\mathrm{T}_{\mathrm{EM}}$ subset (29). Although this study reported no effect of IL-15 therapy on $\mathrm{CD}^{+}$memory $\mathrm{T}$ cells, $\mathrm{CD}^{+} \mathrm{T}_{\mathrm{EM}}$ cells are a minority population of $\mathrm{CD} 4^{+}$memory cells in uninfected rhesus macaques (RMs) (30) and, as indicated above, are often highly depleted in SIV infection $(2,7)$, making it easy to miss specific changes in this subset. Indeed, the ability of IL-15 to dramatically enhance NHP CD $4^{+}$memory responses to immunization (31), to induce $\mathrm{T}_{\mathrm{EM}}$ cell-associated markers such as CCR5 on 
A

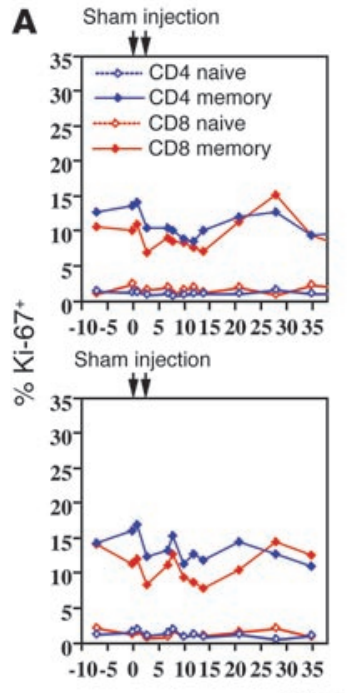

Time (days)

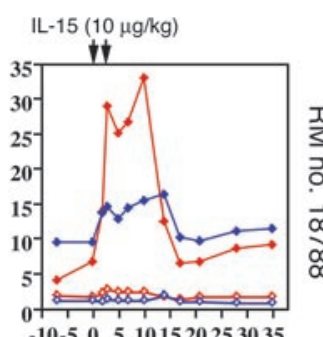

-10-5 05101520253035 IL-15 $(10 \mu \mathrm{g} / \mathrm{kg})$

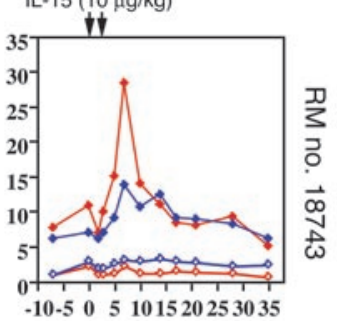

B

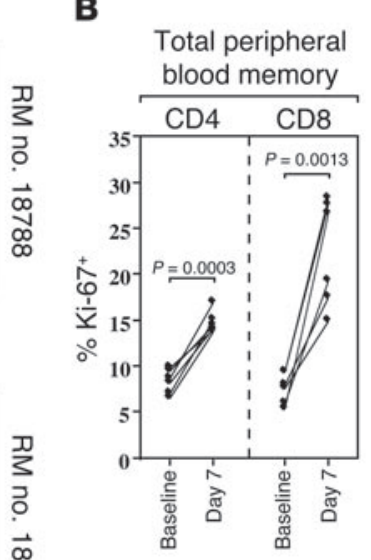

Figure 1

IL-15 induces memory, but not naive, $\mathrm{CD}^{+}{ }^{+}$and $\mathrm{CD} 8^{+} \mathrm{T}$ cells to proliferate. (A) The fraction of cells expressing the proliferation marker $\mathrm{Ki}-67$ was determined in phenotypically defined naive versus memory, $\mathrm{CD} 4^{+}$and $\mathrm{CD} 8^{+}$ $T$ cells from the peripheral blood of 2 representative, normal RMs that were given sham injections first, followed by IL-15 injections 70 days later. (B) The change in the fraction of total $\mathrm{CD}^{+}$or $\mathrm{CD}^{+}$, peripheral blood memory $T$ cells expressing Ki-67 from baseline (defined as the average of the day -7 and day 0 values) to day 7 after the first dose is shown for all 6 RMs that were given the 2-dose IL-15 regimen. (C) The figure shows the correlated expression of CD28 and CCR7 on gated CD4+ and $\mathrm{CD}^{+}$memory $\mathrm{T}$ cells from the peripheral blood of a typical adult RM. Note that the double-negative $T_{E M}$ subset dominates the circulating $\mathrm{CD}^{+}$memory $\mathrm{T}$ cell population but constitutes only a very minor component of $\mathrm{CD} 4^{+}$memory $\mathrm{T}$ cells. $\mathrm{CD} 4^{+}$and $\mathrm{CD} 8^{+}$memory $\mathrm{T}$ cells in blood also differ in the presence of a significant CD28$\mathrm{CCR} 7^{+}$subset in the latter, but not the former, population. (D) The figure shows the typical profiles of CD28 versus CCR7 expression on lung airspace and smallintestinal mucosal CD4+ and CD8+ memory T cells of an adult RM. Note that the vast majority of these memory $T$ cells display either a CD28+CCR7- transitional or a CD28-CCR7- ${ }^{-}$EM phenotype.
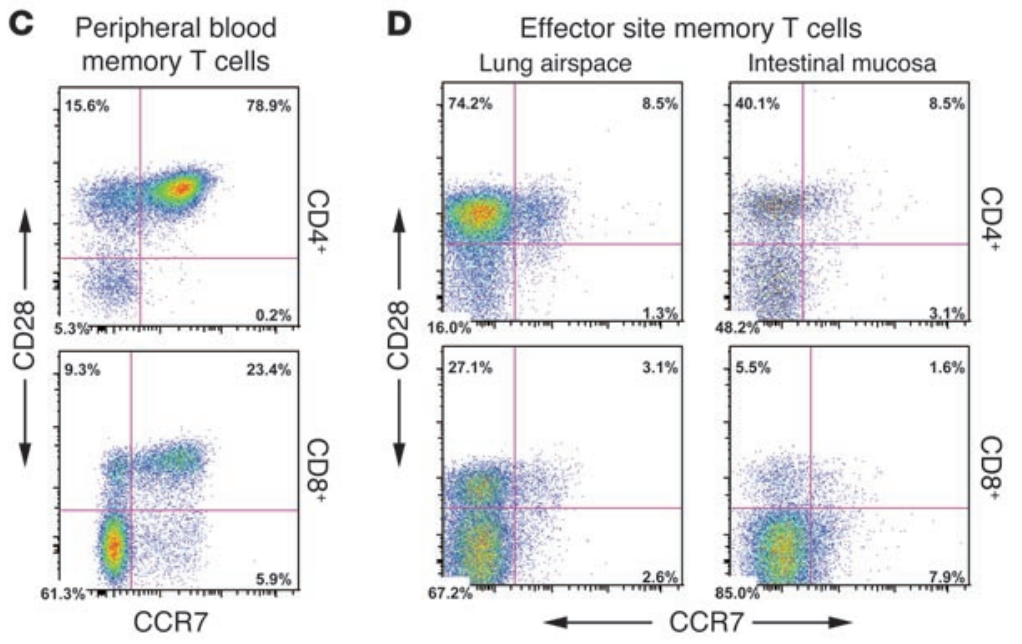

human $\mathrm{CD}^{+}$memory $\mathrm{T}$ cells (32), and to specifically drive proliferation of the human $\mathrm{CD}^{+} \mathrm{T}_{\mathrm{EM}}$ subset in vitro (33) suggests that IL-15 may, in fact, play a role in $\mathrm{CD}^{+} \mathrm{T}_{\mathrm{EM}}$ cell development and homeostasis in primates. Here, we use the RM model to critically evaluate this hypothesis. Our results confirm the specific ability of IL-15 to potently induce proliferation of CD8 ${ }^{+} \mathrm{T}_{\mathrm{EM}}$ cells, with little effect on $\mathrm{CD}^{+} \mathrm{T}_{\mathrm{CM}}$ cells, but, most significantly, unequivocally demonstrate that this cytokine has similar activity on $\mathrm{CD}^{+}$ $\mathrm{T}_{\mathrm{EM}}$ cells. Moreover, we demonstrate that IL-15 increases the flux of long-lived $\mathrm{CD}^{+} \mathrm{T}$ cells into extralymphoid effector sites and induces $\mathrm{CD}^{+} \mathrm{T}_{\mathrm{EM}}$ cell proliferation in SIV-infected RMs undergoing ART. Thus, IL-15, in contrast to either IL-2 or IL-7, selectively expands the $\mathrm{CD}^{+}$and $\mathrm{CD}^{+} \mathrm{T}_{\mathrm{EM}}$ cell compartments, suggesting that this cytokine might have unique therapeutic efficacy in the reconstitution of $\mathrm{CD}^{+} \mathrm{T}$ cell populations in the extralymphoid tissues of $\mathrm{HIV}^{+}$subjects with effective viral suppression.

\section{Results}

$\mathrm{CD}^{+}$and $\mathrm{CD} 8^{+}$memory, but not naive, $\mathrm{T}$ cells proliferate in vivo in response to $I L-15$. Our initial studies established that twice-weekly administration of $10 \mu \mathrm{g} / \mathrm{kg}$ rhesus IL-15 significantly expands the $\mathrm{CD}^{+}$memory $\mathrm{T}$ cell response to tetanus toxoid in healthy RMs
(31). We therefore assessed the ability of this IL-15 regimen to initiate in vivo proliferation of $\mathrm{CD}^{+}$and $\mathrm{CD}^{+}$, naive and memory $\mathrm{T}$ cells in healthy adult RMs (see Methods for naive/memory delineation criteria). Proliferative activity was monitored by flow cytometric evaluation of Ki-67 antigen, the expression of which has previously been shown to reflect $S$ phase in the preceding 4-7 days (30). As expected, sham injections did not affect the proliferative activity in any T cell subset, but 2 doses of IL-15, given 3 days apart, were sufficient to systematically increase proliferation of memory, but not naive, $\mathrm{T}$ cells in both the $\mathrm{CD}^{+}$and the $\mathrm{CD} 8^{+}$lineage (Figure $1 \mathrm{~A})$. In general, an increasing percentage of $\mathrm{Ki}^{-} 67^{+}, \mathrm{CD}^{+}$, or $\mathrm{CD}^{+}$memory $\mathrm{T}$ cells was clearly apparent at 5 days after the first IL-15 dose, with levels peaking at day 7-10 and returning to baseline by day 14-17. Among the 6 RMs assessed in this experiment, the baseline-to-day- 7 change in percentage $\mathrm{Ki}-67^{+}$was an average of 2.3-fold higher for $\mathrm{CD}^{+}$memory $\mathrm{T}$ cells than for $\mathrm{CD}^{+}$memory $\mathrm{T}$ cells, but statistically significant for both lineages (Figure 1B).

IL-15 preferentially acts on the $T_{E M}$ subset of both $C D 4^{+}$and $C D 8^{+}$ $T$ cells. In vitro studies with human $\mathrm{CD} 4^{+}$memory $\mathrm{T}$ cells have demonstrated that IL-15 preferentially increases proliferation of CCR7- $\mathrm{T}_{\mathrm{EM}}$ cells as compared with CCR7 ${ }^{+} \mathrm{T}_{\mathrm{CM}}$ cells $(4,33)$. In RMs, the $\mathrm{T}_{\mathrm{CM}}$-to- $\mathrm{T}_{\mathrm{EM}}$ differentiation pathway was initially validated 
A $\mathrm{CD}^{+}$memory T cells IL-15 $(10 \mu \mathrm{g} / \mathrm{kg})$
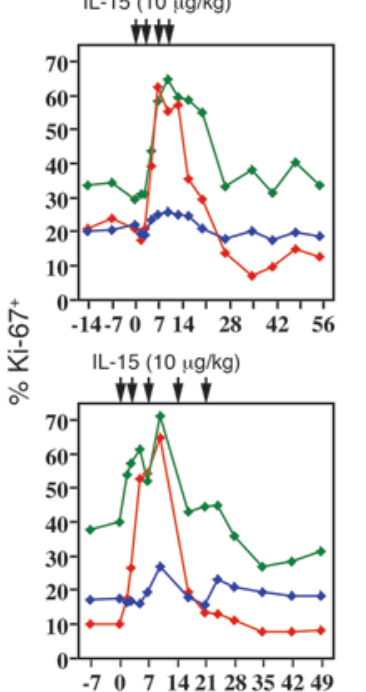

Time
CD8 ${ }^{+}$memory T cells

$\mathrm{IL}-15(10 \mu \mathrm{g} / \mathrm{kg})$
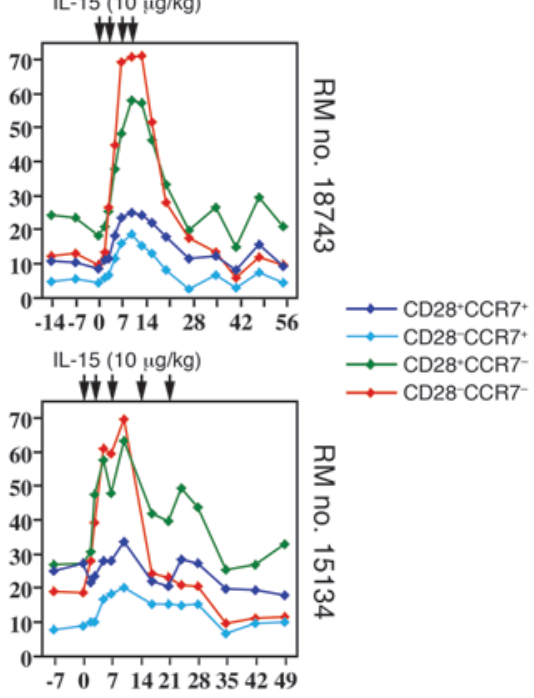

刃刃

\section{资 $\vec{n}$ $\frac{9}{9}$}

(days)

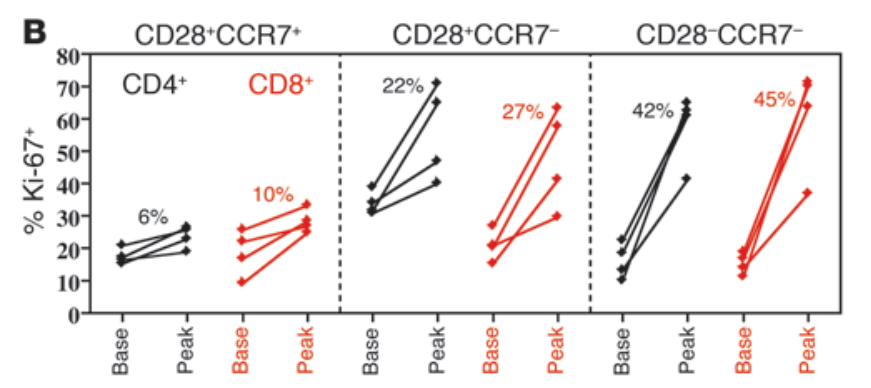

\section{C}

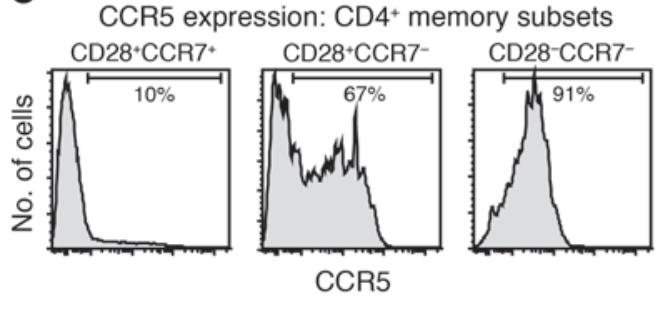

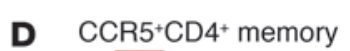

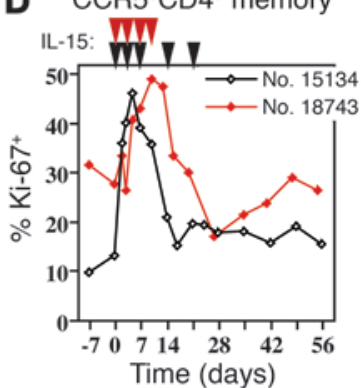

\section{Figure 2}

IL-15 selectively acts on $\mathrm{T}_{\mathrm{EM}}$ and transitional memory T cells. (A) The $\mathrm{CD}^{+}{ }^{+}$and $\mathrm{CD}^{+}$memory $\mathrm{T}$ cell subsets defined by CD28 and CCR7 expression (see Figure 1C) in peripheral blood were assessed for expression of Ki- 67 before, during, and after IL-15 treatment (arrows). Note that CD4+ memory cells lack a significant $\mathrm{CD} 28^{-} \mathrm{CCR} 7{ }^{+}$component, accounting for why only 3 populations are shown for this lineage. (B) The change in percentage Ki-67+ from baseline (the average of day -7 and day 0 values) to peak (either day 7 or day 10 ) is shown for the designated CD4+ (black) and $\mathrm{CD}^{+}$(red) memory subsets in 4 different RMs that received at least 3 doses of IL-15 $(10 \mu \mathrm{g} / \mathrm{kg})$ on days 0,3 , and 7 . The IL-15-induced changes in percentage $\mathrm{Ki}-67$ for each of the 3 comparable CD4 ${ }^{+}$ versus $\mathrm{CD}^{+}$memory subsets (means provided in the figure) were not significantly different. (C) The figure shows the expression of CCR5 by the CD4+ memory subsets defined by CD28 and CCR7 in the peripheral blood of a representative adult RM. (D) The fraction of $\mathrm{CCR}^{+}, \mathrm{CD} 4^{+}$peripheral blood memory $\mathrm{T}$ cells expressing Ki-67 is shown before, during, and after IL-15 treatment (arrows; $10 \mu \mathrm{g} / \mathrm{kg}$ ) in the same 2 representative RMs depicted in $\mathbf{A}$. As would be expected based on the staining pattern shown in C, IL-15 induced a substantial increase in proliferation within the CCR5-expressing, CD4+ memory population.

$\mathrm{T}$ cell population, making it necessary to specifically focus on the phenotypically defined subsets to visualize $\mathrm{CD}^{+} \mathrm{T}_{\mathrm{EM}}$ cell regulation in peripheral blood. Therefore, to evaluate the possibility that IL-15 preferentially acts on $\mathrm{CD}^{+} \mathrm{T}_{\mathrm{EM}}$ cells in vivo, we assessed the Ki-67-defined proliferative activity of the CD28/CCR7-defined, $\mathrm{CD}^{+}$and $\mathrm{CD}^{+}$ memory subsets before, during, and after IL-15 treatment of normal RMs.

As shown in Figure 2A, IL-15 administration resulted in a dramatic increase in proliferative activity among the CD28-CCR7- memory subsets, both $\mathrm{CD}^{+}$and $\mathrm{CD}^{+}$, and to a lesser extent the $\mathrm{CD} 28^{+} \mathrm{CCR} 7^{-}$transitional populations. In contrast, proliferation of both $\mathrm{CD} 4^{+}$and $\mathrm{CD} 8^{+}\left(\mathrm{CCR} 7^{+} \mathrm{CD} 28^{+}\right)$ $\mathrm{T}_{\mathrm{CM}}$ cells and the $\mathrm{CD} 8^{+}, \mathrm{CCR} 7^{+} \mathrm{CD} 28^{-}$subset was only modestly increased by IL-15. The baseline-to-

based on expression of the costimulatory molecule CD28 but has since been refined along the lines of the human paradigm with the CD28-CCR7 ${ }^{-}$phenotype representing fully differentiated $\mathrm{T}_{\mathrm{EM}}$ cells, the $\mathrm{CD} 28^{+} \mathrm{CCR} 7^{+}$phenotype representing $\mathrm{T}_{\mathrm{CM}}$ cells, and the $\mathrm{CD} 28^{+} \mathrm{CCR} 7-$ and $\mathrm{CD} 28^{-} \mathrm{CCR}^{+}$phenotypes representing transitional populations $(4,30,34)$. Figure $1, C$ and $D$, illustrates the $\mathrm{CD}^{+}$and $\mathrm{CD}^{+}$memory populations delineated by these markers in blood and extralymphoid effector sites (lung airspace and intestinal mucosa) in adult RMs. Note first that, in keeping with the $\mathrm{T}_{\mathrm{CM}} / \mathrm{T}_{\mathrm{EM}}$ paradigm, discrete $\mathrm{CD}^{+}$and $\mathrm{CD}^{+} \mathrm{T}_{\mathrm{CM}}$ cell populations circulate in blood but are largely excluded from effector sites (which are composed of variable proportions of CD28 ${ }^{+} \mathrm{CCR} 7^{-}$transitional memory cells, and fully differentiated CD28-CCR7- $\mathrm{T}_{\mathrm{EM}}$ cells). Second, whereas the CD28-CCR7- $\mathrm{T}_{\mathrm{EM}}$ subset constitutes the majority $\mathrm{CD}^{+}$memory population in RM blood, this subset is only a minor component of the circulating $\mathrm{CD} 4^{+}$memory peak increase in proliferation $\left(\Delta \% \mathrm{Ki}-67^{+}\right)$during IL-15 treatment was similar for $\mathrm{CD}^{+}$versus $\mathrm{CD}^{+} \mathrm{T}$ cells within each comparable memory subset (Figure 2B), clearly indicating that the IL- 15 responsiveness of $\mathrm{CD}^{+}$and $\mathrm{CD} 8^{+} \mathrm{T}$ cell lineages is essentially equivalent. As the HIV/SIV coreceptor CCR5 is expressed on over $60 \%$ and over $90 \%$ of the transitional (CD28 $8^{+}$CCR7 -$)$and fully differentiated (CD28-CCR7-) $\mathrm{CD}^{+}, \mathrm{T}_{\mathrm{EM}}$ subsets, respectively (Figure $2 \mathrm{C}$ ), it is not surprising that IL-15 specifically increases the proliferative activity of $\mathrm{CCR}^{+}, \mathrm{CD}^{+}$memory $\mathrm{T}$ cells (Figure 2D). These data indicate that IL-15 has the capacity to directly influence the regeneration of the $T$ cells most efficiently targeted by HIV/SIV.

IL-15 and IL-2 receptors share both $\beta$ and $\gamma$ chains, differing only in their $\alpha$ chains, and the growth-promoting activities of these cytokines can have considerable overlap $(17,18,31)$. Nevertheless, assessment of the in vivo effects of IL-2 in our system revealed a decidedly different pattern of activity (Figure 3). IL-2 was able to significantly 

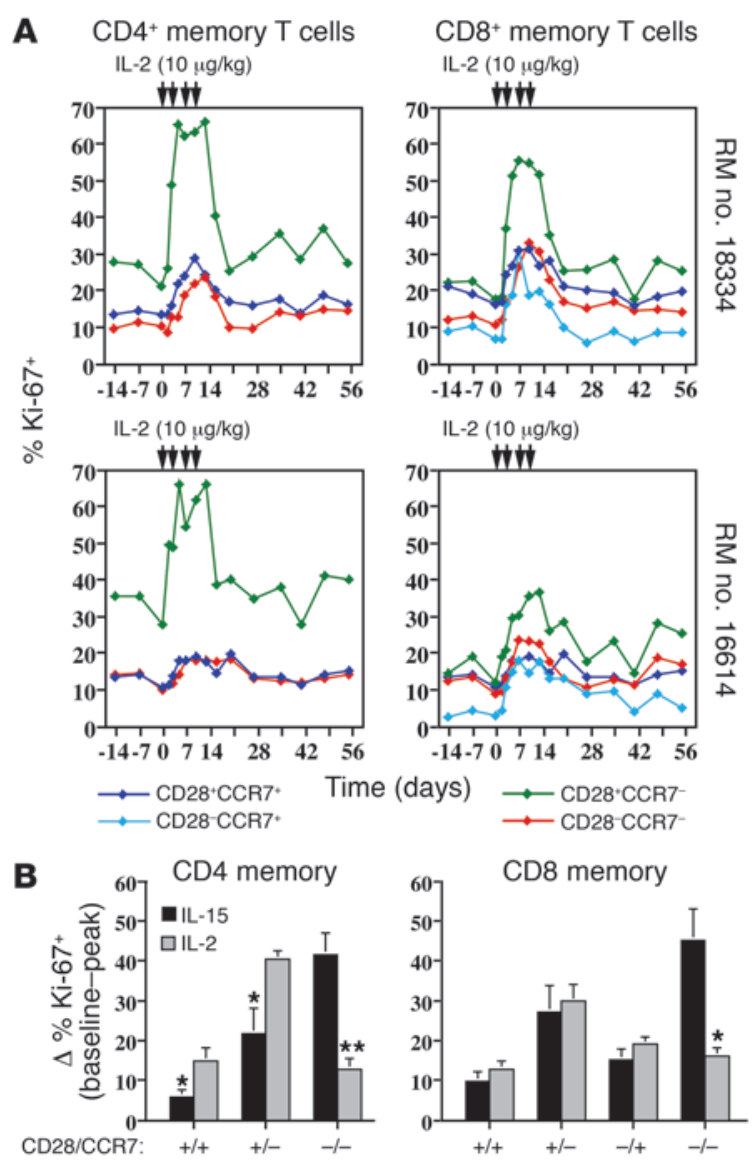

increase proliferation of the $\mathrm{CD}^{+}$and $\mathrm{CD}^{+}, \mathrm{CD} 28^{+} \mathrm{CCR} 7^{-}$transitional subsets but, in contrast to IL-15 (Figure 3B), had little effect on fully differentiated CD28-CCR7- $\mathrm{T}_{\mathrm{EM}}$ cells, either $\mathrm{CD}^{+}$or $\mathrm{CD}^{+}$. As IL-7 has been reported to potently initiate proliferation among $\mathrm{CD}^{+}$and $\mathrm{CD}^{+}$naive $\mathrm{T}$ cells and $\mathrm{T}_{\mathrm{CM}}$ cells in NHPs (21), these data indicated that among the major pro-proliferative, common $\gamma$ chain family cytokines, only IL-15 manifests $\mathrm{T}_{\mathrm{EM}}$ cell selectivity.

In our assessment of different IL-15 dosing regimens, we observed that extending treatment past day 10 often failed to maintain peak $\mathrm{T}_{\mathrm{EM}}$ cell proliferative responses (see, for example, RM no. 15134 in Figure 2A). This late resistance to IL-15 was clearly not due to the development of anti-IL-15 antibodies, as redosing at longer time intervals resulted in full responsiveness (Figure 4A), and no evidence of antibodies to this rhesus IL-15 preparation have been detected in similarly or more extensively treated RMs (F. Villinger, unpublished data). Closer scrutiny of the Ki-67 profiles of $\mathrm{CD}^{+} \mathrm{T}_{\mathrm{EM}}$ cells in IL-15-treated RMs (Figure 4B) indicates that the proliferative response was first noticeable at days 3 and 5 as an increase in Ki-67dim-intermediate ${ }^{+}$cells (black arrows), consistent with new cells being recruited into the cell cycle. These cells appear to have proceeded as a group to become Ki-6 $7^{\text {bight }}{ }^{+}$by day 7, and then Ki-67dim-intermediate+ by day 10 (blue arrows), consistent with coordinate progression through the cell cycle and back into $\mathrm{G}_{0}$. In RMs given at least $4 \mathrm{IL}-15$ doses over 2 weeks, a second, smaller Ki-6 $7^{\text {bright+ }}$ peak appeared at day 10 (red arrow). At day 14, a smaller Ki-67 ${ }^{\text {dim-intermediate+ }}$ peak was noted (red arrow), consistent with the cell cycle progression of the Ki-67bright+ cells found at day 10 . Finally, a third, small Ki-67 ${ }^{\text {bright }}{ }^{+}$peak appeared at day

\section{Figure 3}

CD28-, CCR7- $\mathrm{T}_{\mathrm{EM}}$ cells are poorly responsive to IL-2. (A) The CD4+ and $\mathrm{CD}^{+}$memory $\mathrm{T}$ cell subsets defined by CD28 and CCR7 expression in the peripheral blood in 2 representative RMs (of 4 total) were assessed for expression of Ki-67 before, during, and after 2 weeks of twice-weekly administration of IL-2. Note that IL-2 preferentially induced proliferation in the $\mathrm{CD} 28^{+} \mathrm{CCR} 7^{-}$component of both the CD4+ and the $\mathrm{CD} 8^{+}$memory populations. (B) The mean ( \pm SEM) change in percentage $\mathrm{Ki}-67$ from baseline (the average of day -7 and day 0 values) to peak response (day 7 or 10 after the first cytokine dose) is shown for the CD28/CCR7-defined peripheral blood memory T cell subsets in all $4 \mathrm{IL}-2$-treated RMs, and the $4 \mathrm{RMs}$ that received at least 3 doses of IL-15 (the pre-peak doses on days 0,3 , and 7, matching the pre-peak IL-2 dosing schedule). While IL-2 demonstrated a superior (to $\mathrm{CD}^{+}$) or similar (to $\mathrm{CD}^{+}$) ability to induce proliferation among CD28 ${ }^{+}$CCR7- transitional memory $T$ cells, IL-15 was dramatically better than IL-2 in initiating proliferation within both the $\mathrm{CD}^{+}$and the CD8 ${ }^{+}$, CD28-CCR7 ${ }^{-} \mathrm{T}_{\mathrm{EM}}$ subsets. ${ }^{*} 0.05<P<0.005 ;{ }^{* *} P<0.005$.

14, which dissipated by day 17 (green arrows). These data strongly suggest that the initial IL-15 dose(s) appears to find the majority of response-capable cells, producing a large "wave" of coordinate cell cycle progression. Successive doses find progressively fewer response-capable cells and therefore elicit progressively smaller proliferative waves. This response pattern suggests that responding cells may become refractory to IL-15-mediated signals after their initial response, and/or that IL-15-responsive cells are limiting and take time to regenerate.

$T_{E M}$ cells produced in response to IL-15 are long-lived and rapidly migrate to an extralymphoid effector site. The selective proliferation of $\mathrm{T}_{\mathrm{EM}}$ cells induced by IL-15 might be expected to expand this population, both relative to their $\mathrm{T}_{\mathrm{CM}}$ counterparts and in absolute numbers. Analysis of the representation of the CD28/CCR7-defined memory $\mathrm{T}$ cell subsets in blood demonstrated that such expansion either was not observed or was of low amplitude and transient, as exemplified by RMs no. 15134 and no. 18743, respectively (Figure $5 \mathrm{~A})$. Similar results were observed with analysis of absolute counts of these subsets in blood (Figure 5B). These observations suggest that the Ki- $67^{+}$cells induced by IL-15 (a) did not actually proliferate, (b) were short-lived, or (c) rapidly emigrated to extravascular sites. To address these possibilities, 6 RMs given 2 doses of IL-15 on days 0 and 3 were given the thymidine analogue 5-bromo-2'deoxyuridine (BrdU) on days 4-7, and the BrdU uptake and decay of the $\mathrm{T}_{\mathrm{EM}}$ cells in the blood and pulmonary airspaces (obtained via bronchoalveolar lavage; $\mathrm{BAL}$ ) of these RMs were compared with those of a large cohort of identically assessed RMs that were not given IL-15 $(7,30)$. As shown in Figure 6A, the peak BrdU uptake of $\mathrm{CD}_{28}^{-}, \mathrm{CD}^{+}$, and $\mathrm{CD}^{+} \mathrm{T}$ cells in blood immediately after the labeling period was 4 - to 5-fold higher in the IL-15-treated animals than in controls, clearly indicating that IL-15 increases the number of cells undergoing the $S$ phase of the cell cycle. The frequency of BrdU-labeled CD28- $\mathrm{CD}^{+}$, and $\mathrm{CD}^{+} \mathrm{T}$ cells diminished $20-30 \%$ in the first 4 days after labeling, in concert with loss of Ki-67 expression, but the decay curves remained almost flat thereafter at labeling frequencies that remained 4- to 5-fold higher than in control RMs. Indeed, in 2 IL-15-treated RMs followed in the long term, a more than 5-fold difference in labeling frequency compared with that of controls was still present 9 months after the initial IL-15-induced proliferative burst (data not shown).

Peak appearance of BrdU-labeled memory T cells in extralymphoid sites such as the pulmonary airspaces is delayed 4-7 days 


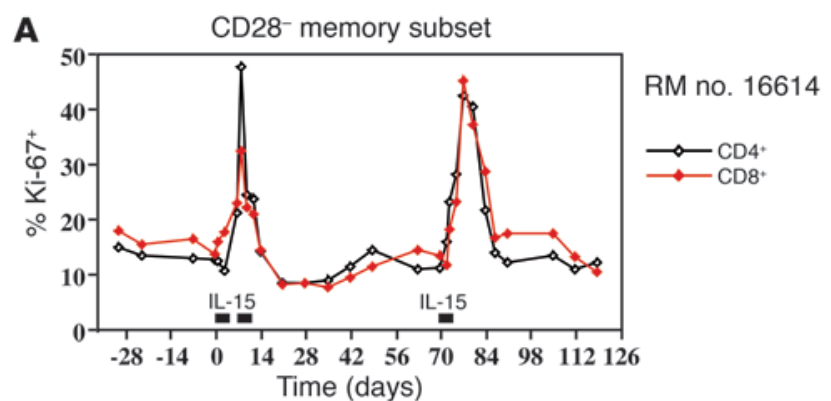

B RM no. 18743: CD28-CCR7- CD4+ memory

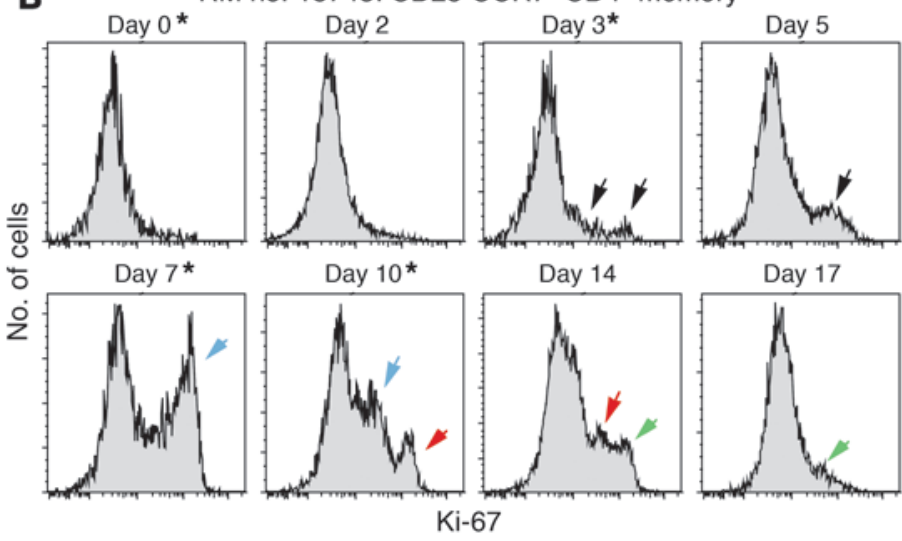

compared with that in blood, and these cells have largely downregulated $\mathrm{Ki}-67$ expression at the time of first appearance in BAL (7). These findings indicate that these sites are largely supplied by emigration of memory $T$ cells that have recently completed proliferation elsewhere. As shown in Figure 6B, the administration of IL-15 before BrdU pulsing increased the average peak accumulation of $\mathrm{BrdU}^{+} \mathrm{CD}^{+}$and $\mathrm{CD}^{+}$memory $\mathrm{T}$ cells in BAL specimens approximately 3 -fold over that in untreated controls. Subsequent decay of the BrdU-labeled BAL T cells in IL-15-treated RMs was parallel to that in untreated RMs, indicating that the turnover of the IL-15-induced T cells in pulmonary airspaces is not accelerated relative to that in normal controls. Taken together, the blood and BAL BrdU data indicate that IL-15-induced $\mathrm{CD}^{+}$and $\mathrm{CD}^{+}$ memory $T$ cell proliferation results in long-lived progeny that efficiently disperse into extralymphoid effector sites.

$T_{E M}$ cell sensitivity to IL-15 is lost with uncontrolled SIV infection but is restored with pharmacologic suppression of viral replication. As restoration of the depleted $\mathrm{CD}^{+} \mathrm{T}_{\mathrm{EM}}$ cell compartment would be expected to be beneficial to HIV-infected individuals, we examined the

\section{Figure 5}

IL-15-responsive memory subsets do not accumulate in peripheral blood. (A) The fraction of total CD4 ${ }^{+}$and $\mathrm{CD} 8^{+}$memory $\mathrm{T}$ cells in each of the CD28/CCR7-defined subsets in blood (see Figure 1A) is shown before, during, and after IL-15 treatment (the same IL-15-treated RMs shown in Figure 2). Note that despite vast differences in IL-15-induced proliferation between these subsets, their relative frequencies in blood (particularly the $\mathrm{T}_{\mathrm{CM}}$-to- $\mathrm{T}_{\mathrm{EM}}$ ratio) either did not change or changed only transiently. (B) The absolute number of $\mathrm{CD}^{+}$and $\mathrm{CD} 8^{+} \mathrm{CD} 28^{-} \mathrm{CCR} 7^{-}$ $T_{E M}$ cells is shown in the same RMs. Again, profound IL-15-induced proliferation resulted in only transiently increased numbers of $T_{E M}$ cells in peripheral blood.

\section{Figure 4}

IL-15 responsiveness is limited by the availability of responsecapable cells, but not by development of an anti-IL-15 antibody response. (A) The expression of $\mathrm{Ki}-67$ within the CD28- subset of circulating $\mathrm{CD}^{+}$and $\mathrm{CD} 8^{+}$memory $\mathrm{T}$ cells is shown over time in a healthy, adult (IL-15-naive) RM receiving 2 courses of IL-15 therapy 70 days apart. Each black box represents 2 doses of IL-15 (each dose $10 \mu \mathrm{g} / \mathrm{kg}$ ). Note that the second response was of a magnitude similar to or greater than that of the initial response. (B) The figure shows successive histograms of Ki-67 expression on gated CD28-CCR7-, CD4+ memory T cells from an RM (no. 18743) that received $10 \mu \mathrm{g} / \mathrm{kg} \mathrm{IL}-15$ on days $0,3,7$, and 10 (see Figure 2 for overall quantitative data). The arrows (black, blue, red, and green) delineate successive waves of $\mathrm{Ki}-67$ expression (see text). *IL-15 dose given on indicated days.

effect of IL-15 on memory subset proliferation in SIV-infected monkeys. Figure 7A shows the effect of IL-15 treatment on RMs with stable, untreated chronic-phase SIVmac239 infection, with plasma viral loads in the range of $5 \times 10^{5}$ to $5 \times 10^{7}$ copies/ml. Consistent with previous studies (7), steady-state memory $\mathrm{T}$ cell proliferative activity in these infected RMs was 2- to 4-fold higher than that in uninfected animals (compare with Figure 2). This increased steady-state proliferation was found in both $\mathrm{T}_{\mathrm{EM}}$ and $\mathrm{T}_{\mathrm{CM}}$ subsets and, although somewhat higher in $\mathrm{CD}^{+}$memory subsets, involved $\mathrm{CD}^{+}$memory subsets as well. In 4 of 6 studied RMs (nos. 21462 and 21102 shown), circulating $\mathrm{CD}^{+} \mathrm{T}_{\mathrm{EM}}$ cells were substantially reduced by infection, but detectable; in the other 2 studied RMs (no. 21522 shown), this depletion was essentially complete. Administration

A

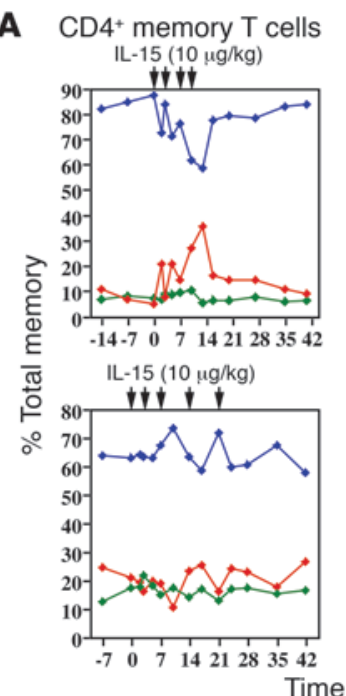

B

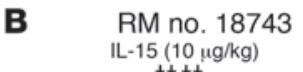
Time (days)

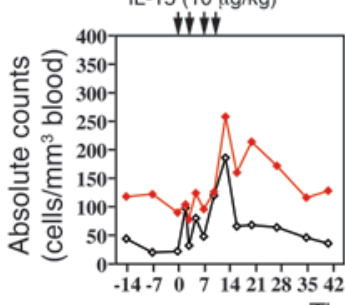

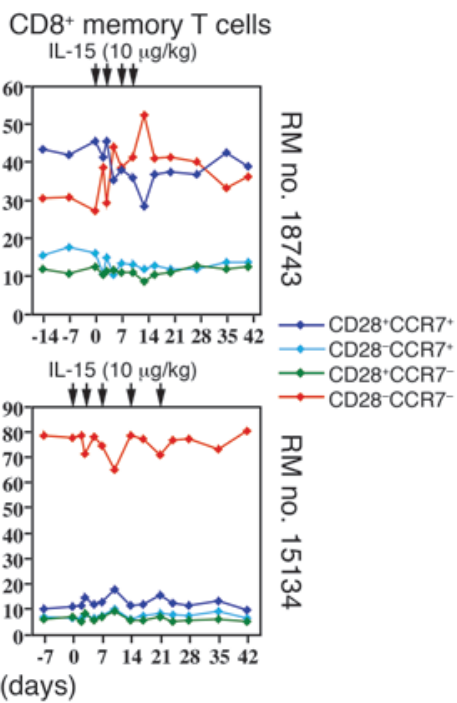

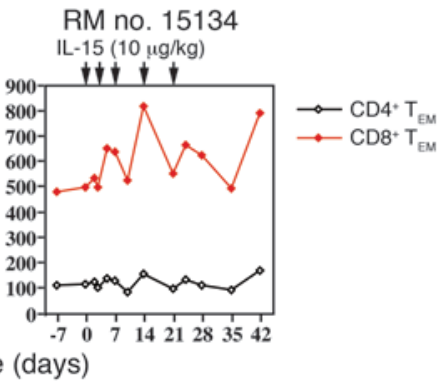


A
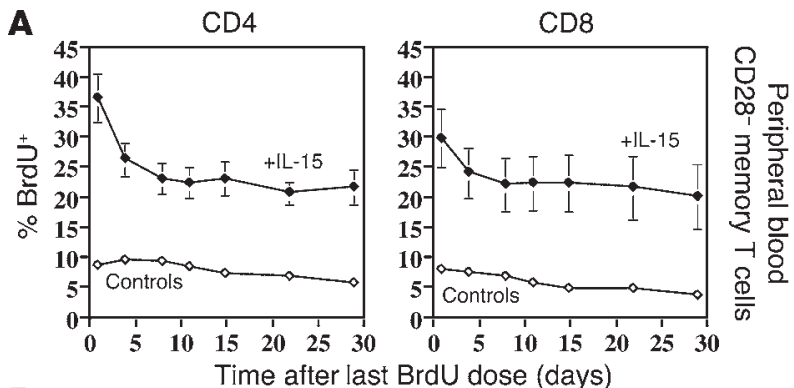

B

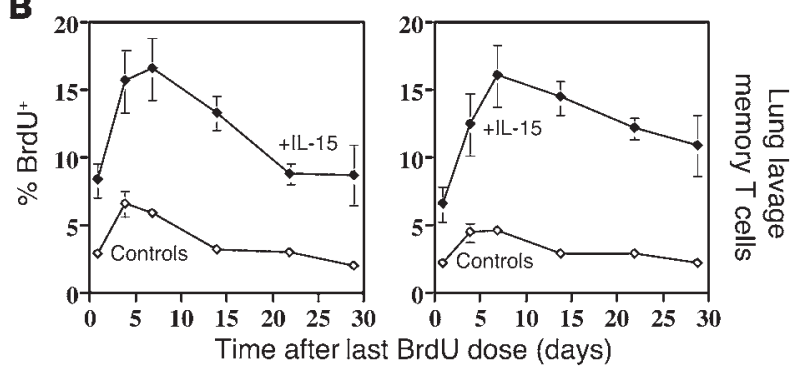

IL-15 $(10 \mu \mathrm{g} / \mathrm{kg})$ at day $-7,-4$

$\mathrm{BrdU}(30 \mu \mathrm{g} / \mathrm{kg})$ at day $-3,-2,-1,0$

\section{Figure 6}

The progeny of IL-15-stimulated T cells are long-lived and rapidly migrate into an extralymphoid effector site. The $6 \mathrm{RMs}$ that received a 2-dose IL-15 regimen $(10 \mu \mathrm{g} / \mathrm{kg} 3$ days apart) were pulsed with 30 $\mathrm{mg} / \mathrm{kg} \mathrm{BrdU}$ on the 4 days after the second IL-15 dose, and then subsequently assessed for BrdU incorporation and decay in the CD28$\left(\mathrm{CD} 4^{+}\right.$and $\left.\mathrm{CD}^{+}\right)$memory subsets in peripheral blood $(\mathbf{A})$ and the overall $\left(C D 4^{+}\right.$and $\left.C D 8^{+}\right)$memory populations in BAL specimens $(B)$. These IL-15-treated RMs were compared with a cohort of 12 (A) or 16 (B) untreated RMs that were subjected to the same 4-day BrdU labeling regimen. The figure shows the mean percentage $\mathrm{BrdU}^{+}$cells ( \pm SEM) in the populations indicated in the IL-15-treated (filled diamonds) versus control RMs (open diamonds), with the day of the last BrdU dose designated day 0 . Note that for many data points, the SEM is sufficiently small so that the error bars are obscured by the symbols. The difference in $\mathrm{BrdU}^{+}$cell frequencies between IL-15-treated and control RMs in the blood effector memory populations was significant at $P<0.0001$ and $P<0.0004$ at all time points for $\mathrm{CD}^{+}$and $\mathrm{CD} 8^{+} \mathrm{T}$ cells, respectively. In BAL, this difference was significant at $P<0.0004$ at all time points for both $\mathrm{CD} 4^{+}$and $\mathrm{CD} 8^{+} \mathrm{T}$ cells.

of 4 doses of IL-15 at either $10 \mu \mathrm{g} / \mathrm{kg}$ or $50 \mu \mathrm{g} / \mathrm{kg}$ per dose over 2 weeks to these infected RMs had little or no effect on proliferation of CD4 ${ }^{+} \mathrm{T}_{\mathrm{EM}}$ cells and transitional memory cells (Figures 7A and $8 \mathrm{~B})$. Among $\mathrm{CD}^{+} \mathrm{T}_{\mathrm{EM}}$ cells, IL-15 elicited a blunted increase in percentage Ki-67 in all these RMs, which was noticeably delayed in the 2 animals receiving the lower IL-15 dose. Among the CD8 ${ }^{+}$, CD28 ${ }^{+}$CCR7- subset, only RMs treated with the $50 \mu \mathrm{g} / \mathrm{kg}$ dose of IL-15 manifested a modest proliferative increase. Significantly, plasma viral loads were not increased by IL-15 therapy; if anything, there was a tendency in several RMs toward a modest, transient reduction in viral loads during therapy (Figure 9A).

SIV infection per se does not abolish IL-15 responsiveness, as administration of IL-15 to an SIV-infected animal with spontaneous, high-level control of viral replication (plateau-phase plasma viral loads $<5 \times 10^{2}$ copies $/ \mathrm{ml}$ ) showed a $\mathrm{CD}^{+}$and $\mathrm{CD}^{+} \mathrm{T}_{\mathrm{EM}}$ cell proliferative response similar to that of uninfected RMs (Figures $7 \mathrm{~B}$ and $8 \mathrm{~B}$ ). Moreover, when 5 typical SIV-infected RMs were provided ART (35), including 3 RMs previously studied with active infections, plasma viral loads were reduced by $3-5$ logs, $C D 4^{+} \mathrm{T}_{\mathrm{EM}}$ cells became detectable in blood in all animals, steady-state $\mathrm{CD}^{+}$ and $\mathrm{CD}^{+}$memory subset proliferative activity was substantially reduced, and IL-15 administration at either the 10 or the $50 \mu \mathrm{g} / \mathrm{kg}$ dose level was able to significantly increase the proliferative activity within the $\mathrm{CD}^{+}$and $\mathrm{CD}^{+} \mathrm{T}_{\mathrm{EM}}$ and $\mathrm{CD} 28^{+} \mathrm{CCR} 7^{-}$transitional subsets (Figure $8, \mathrm{~A}$ and $\mathrm{B}$ ). The IL-15-induced change in percentage Ki-67 (e.g., baseline to peak) among $\mathrm{CD}^{+}$and $\mathrm{CD}^{+} \mathrm{T}_{\mathrm{EM}}$ cells in ART-treated, SIV-infected RMs was found to be significantly different from that in untreated SIV-infected RMs $(P<0.02)$. The average amplitude of the percentage Ki-67 change in ART-treated RMs was reduced compared with that in uninfected RMs, but this difference did not achieve statistical significance. Moreover, it was evident from the data shown in Figure $8 \mathrm{~B}$ that peak frequencies of proliferating $\left(\mathrm{Ki}-67^{+}\right) \mathrm{T}_{\mathrm{EM}}$ cells in ART-treated RMs after IL-15 administration were often in the same range as those in the uninfected animals given IL-15, the primary difference being the higher baseline proliferation of the former group. As in uninfected RMs, the majority of $\mathrm{CD}^{+}{ }^{+}$transitional memory and $\mathrm{T}_{\mathrm{EM}}$ cells induced to proliferate by IL-15 in ART-treated RMs expressed the CCR5 coreceptor (data not shown). It is therefore noteworthy that despite this IL-15-induced expansion of SIV “targets," IL-15 therapy was not associated with an increase in plasma viral loads in these animals (Figure 9B).

We also explored the IL-15 responsiveness of memory T cells specific for the potentially opportunistic pathogen rhesus cytomegalovirus (RhCMV) and SIV itself in 3 RMs (nos. 21021, 21046, and 20955) with controlled SIV infection (1 spontaneous, 2 ART, respectively) and known overall $\mathrm{T}_{\mathrm{EM}}$ cell responsiveness to IL-15 (Figures $7 \mathrm{~B}$ and 8). Not surprisingly, the pre-IL-15-treatment CD28/CCR7 phenotype of the pathogen-specific $\mathrm{T}$ cells in peripheral blood predicted whether IL-15 would influence their proliferative activity (Figure 9C). The RhCMV-specific $\mathrm{CD}^{+}$and $\mathrm{CD}^{+} \mathrm{T}$ cells and the SIVgag-specific $\mathrm{CD}^{+} \mathrm{T}$ cells in blood included a large CD28-CCR7component and showed a clear increase in proliferative activity with IL-15 administration. In contrast, SIVgag-specific $\mathrm{CD}^{+} \mathrm{T}$ cells in blood included virtually no CD28 ${ }^{-}$CCR7- ${ }^{-} \mathrm{T}_{\mathrm{EM}}$ cells and manifested little change in their proliferative status during IL-15 therapy.

\section{Discussion}

The common $\gamma$ chain cytokine family members IL-2, IL-7, and IL-15 share the ability to initiate and/or enhance mature $T$ cell proliferation and, via this mechanism and effects on T cell survival, exert a major influence on peripheral $T$ cell homeostasis (15-19). Despite a plethora of work documenting the consequences of "adding" these cytokines to or "subtracting" them from various immunologic systems and models, the specific, nonredundant role(s) of each of these cytokines in controlling peripheral $\mathrm{T}$ cell population dynamics and function has, to date, not been clearly defined. In this study, we have unequivocally established in an NHP model that the major in vivo pro-proliferative activity of IL-15 on peripheral T cells is not, as has been previously suggested $(15,18,24,26,28,29)$, largely restricted to $\mathrm{CD}^{+}$memory $\mathrm{T}$ cells but, rather, is directed at memory $\mathrm{T}$ cells of either the $\mathrm{CD}^{+}$or the $\mathrm{CD}^{+}$lineage that are either $\mathrm{T}_{\mathrm{EM}}$ or differentiating toward $\mathrm{T}_{\mathrm{EM}}$ (4). Although our data do not distinguish among IL-15 directly inducing $\mathrm{T}_{\mathrm{EM}}$ or transitional memory cells to proliferate, induction occurring indirectly via a distinct cytokine intermediate, and IL-15 acting on $\mathrm{T}_{\mathrm{CM}}$ cell precursors to simultaneously induce proliferation and $\mathrm{T}_{\mathrm{EM}}$ cell differentiation, the ability of IL-15 to preferentially promote proliferation of purified $\mathrm{T}_{\mathrm{EM}}$ 
A

$\mathrm{CD}^{+}$memory T cells int

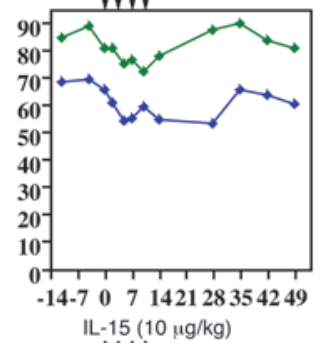

intit

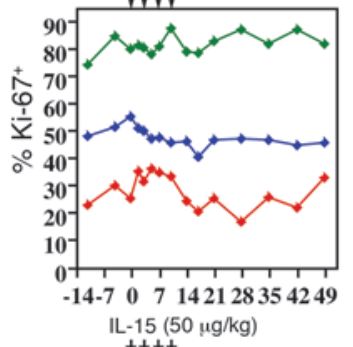

thit

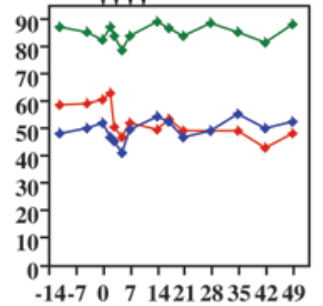

B
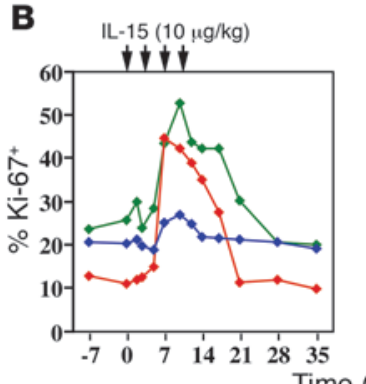

Time (days)
IL-15 $(10 \mu \mathrm{g} / \mathrm{kg})$

Time (days)

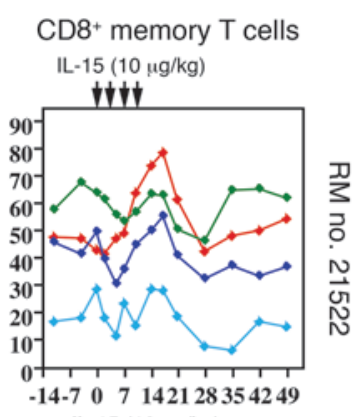

$\mathrm{IL}-15(10 \mu \mathrm{g} / \mathrm{kg})$

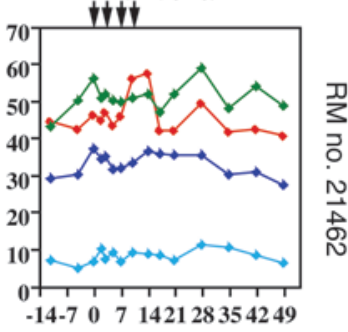

$\mathrm{IL}-15(50 \mu \mathrm{g} / \mathrm{kg})$

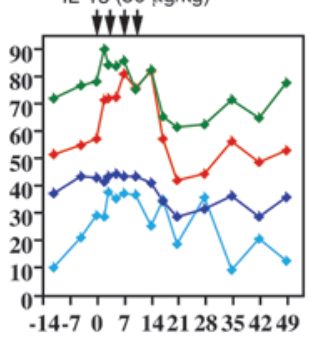

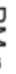
o. 苦

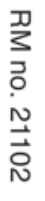
C28.CCR7+ CD28-CCR7
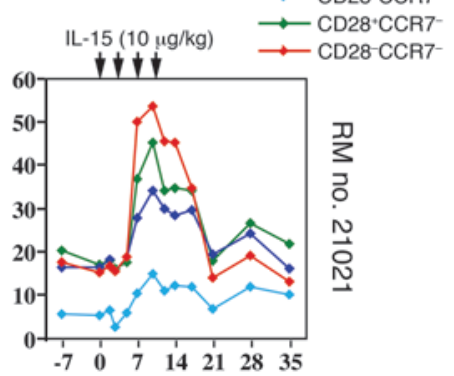

cells in vitro (ref. 33 and L.J. Picker, unpublished data) favors the first possibility. In our studies, the increased proliferation induced by IL-15 resulted in long-lived progeny with the capacity to migrate into lung airspaces, a typical extralymphoid effector site. Thus, IL-15 preferentially expands those populations of $\mathrm{T}$ cells capable of localizing in extralymphoid effector sites and directly responding to pathogen invasion.

Although IL-2 can substitute for IL-15 in some functional activities - for example, the ability to initially amplify antigen-specific $\mathrm{T}$ cell responses $(16-18,20,24,31)$ or, in this study, to induce proliferation of CD28 ${ }^{+}$, CCR7- transitional memory cells - the major in vivo functions of these cytokines appear to be quite distinct. Most notably, IL-2 had little or no effect on the proliferation of fully differentiated (CD28- CCR7-) $\mathrm{T}_{\mathrm{EM}}$ cells and thus does not appear to play as direct a role as IL-15 in the regulation of the extralymphoid $\mathrm{T}$ cell populations. In addition, it is increasingly

\section{Figure 7}

IL-15 responsiveness is diminished in the highly activated immune systems of RMs with uncontrolled SIV infection but remains intact in a spontaneous controller. (A) The figure shows the effects of 2 weeks of twice-weekly IL-15 therapy at the same dose used in previous experiments (10 $\mu \mathrm{g} / \mathrm{kg}$, RMs no. 21522 and no. 21462) and a dose 5 times higher (RM no. 21102) on the expression of Ki-67 by the peripheral blood $\mathrm{CD}^{+}$and $\mathrm{CD}^{+}$memory $\mathrm{T}$ cell subsets defined by CD28 and CCR7 expression in 3 representative RMs (of 6 total) with typical untreated, plateau-phase SIV infection (see Figure 9A for plasma viral loads). Note that circulating CD4+, CD28-CCR7- $\mathrm{T}_{\mathrm{EM}}$ cells were absent in RM no. 21522 because of viral pathogenicity. (B) The same analysis is shown for an SIVmac239-infected RM (no. 21021) with spontaneous control of viral replication (plateau plasma viral loads $<5 \times 10^{2}$ copies $/ \mathrm{ml}$ ) treated with $10 \mu \mathrm{g} / \mathrm{kg} \mathrm{IL-15}$ at the same dosing schedule.

clear that IL-2 has a unique role in the development and maintenance of the regulatory $\mathrm{T}$ cell populations that protect against autoimmunity and counter-regulate $T$ cell responses to exogenous antigens (20). IL-2 was the first of the T cell "growth factors" to be discovered, and as a result, it has been extensively evaluated as a therapeutic approach to $\mathrm{T}$ cell reconstitution (16). Significantly, while long-term, intermittent low-dose IL-2 therapy in HIVinfected individuals has been shown to be efficacious in increasing $\mathrm{CD}^{+} \mathrm{T}$ cell numbers in peripheral blood (36-38), the $\mathrm{CD} 4^{+}$ $\mathrm{T}$ cells increased by these regimens are predominantly naive, and to a lesser extent $\mathrm{T}_{\mathrm{CM}}$, in phenotype (36). The effect of such longterm IL-2 therapy on tissue $\mathrm{CD} 4^{+} \mathrm{T}_{\mathrm{EM}}$ cell populations has not been reported, but efficient repletion of this compartment would not be predicted on the basis of this pattern of activity. Moreover, the expanded naive $\mathrm{CD} 4^{+} \mathrm{T}$ cells in IL-2-treated subjects were demonstrated to express both $\mathrm{CD} 25$ and the forkhead transcription factor P3 (foxP3) (39), suggesting that these cells constitute a regulatory $\mathrm{T}$ cell population and raising the possibility that this population could exacerbate, rather than ameliorate, the immune suppression of HIV-infected subjects (20).

IL-7 also has the capacity to stimulate peripheral $\mathrm{T}$ cell expansion, both by induction of peripheral $\mathrm{T}$ cell proliferation and by support of thymopoiesis $(15,18,19,21,22,40)$. In NHPs, therapeutic IL-7 was found to expand peripheral $\mathrm{CD}^{+} \mathrm{T}$ cells in normal macaques, as well as macaques infected with SIV or subjected to total-body irradiation and autologous stem cell transplantation $(21,22,40,41)$. In these studies, IL-7 appeared to dramatically increase proliferation of both naive and memory phenotype $\mathrm{T}$ cells (among memory, predominantly the $\mathrm{CD} 28^{+}$population), and to induce a memory-like phenotype on the responding naive cells (including induction of memory-like cell surface markers and the ability to synthesize TNF- $\alpha$ and IFN- $\gamma$ ) (21). In preliminary studies, we have found that low-dose IL-7 selectively induces proliferation of $\mathrm{CD}^{+}$and $\mathrm{CD} 8^{+} \mathrm{T}_{\mathrm{CM}}$ cells with little effect on $\mathrm{T}_{\mathrm{EM}}$ cell populations of either lineage (L.J. Picker, unpublished data). These findings, along with the observation that the IL-7 receptor $\alpha$ chain (CD127) (and IL-7 responsiveness) is downregulated with progressive $\mathrm{T}_{\mathrm{EM}}$ differentiation in both humans and NHPs (refs. 42, 43, and L.J. Picker, unpublished data), indicate that IL-7's pro-proliferative activity is primarily focused on $\mathrm{T}$ cells recirculating among secondary lymphoid tissues (naive and $\mathrm{T}_{\mathrm{CM}}$ cells) and likely serves as a major homeostatic regulator of these populations. The data also suggest that at the most stimulatory dosing regimens, therapeutic IL-7 has the capacity to disrupt the normal naive/memory 
A
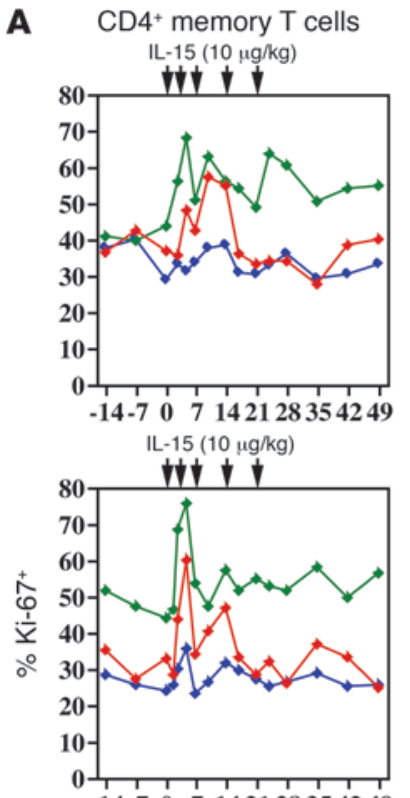

$\begin{array}{rlllll}-14-7 & 0 & 7 & 142128354249\end{array}$ IL-15 $(50 \mu \mathrm{g} / \mathrm{kg})$ it th

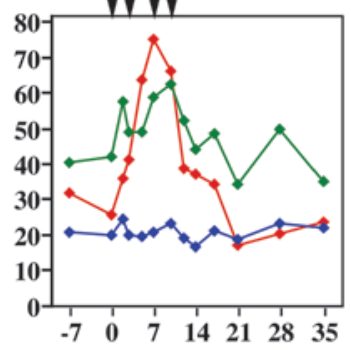
Tim

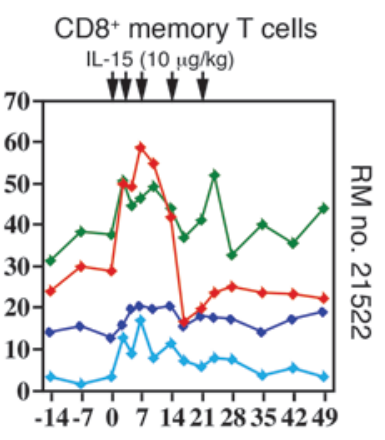

IL-15 $(10 \mu \mathrm{g} / \mathrm{kg})$
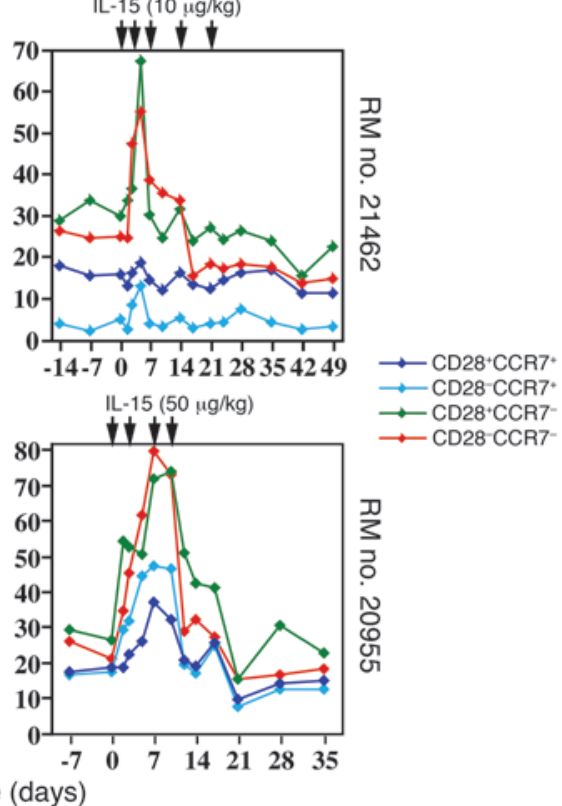

B

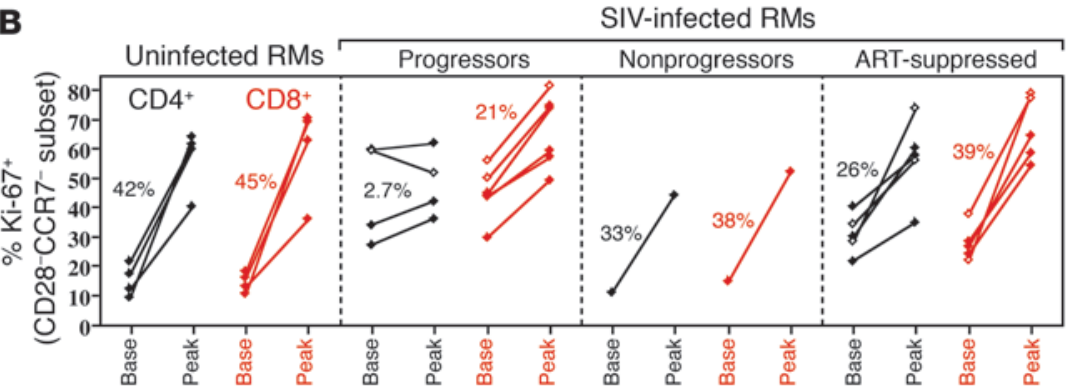

\section{Figure 8}

IL-15 responsiveness is restored with control of viral replication by ART. (A) The figure shows the effects of IL-15 therapy on the expression of Ki- 67 by the peripheral blood $\mathrm{CD}^{+}$and $\mathrm{CD} 8^{+}$memory $\mathrm{T}$ cell subsets defined by CD28 and CCR7 expression in 3 representative SIV-infected RMs (of 5 total) that were treated with ART and achieved a stable 3- to 5-log reduction in plasma viral load. Note that ART restored an IL-15-responsive CD4+, CD28-CCR7- $\mathrm{T}_{\mathrm{EM}}$ cell population in all animals. (B) The maximal effect of IL-15 (baseline to peak) on $\mathrm{CD}^{+}$(black) and CD8+ (red) $\mathrm{T}_{\mathrm{EM}}\left(\mathrm{CD} 28^{-} \mathrm{CCR} 7^{-}\right)$ cell proliferation (percentage $\mathrm{Ki}-67$ ) is shown for all study RMs given at least 3 doses of IL-15 (filled diamonds, $10 \mu \mathrm{g} / \mathrm{kg}$; open diamonds, $50 \mu \mathrm{g} / \mathrm{kg}$ ) on days 0,3 , and 7 . The magnitude of the IL-15induced proliferation in the $\mathrm{CD}^{+}$and $\mathrm{CD}^{+} \mathrm{T}_{\mathrm{EM}}$ cell populations of the uninfected and ART-treated, SIV-infected cohorts (means provided in the figure) was not significantly different; however, the IL-15induced changes in $\mathrm{T}_{\mathrm{EM}}$ cell proliferation in both of these cohorts were significantly different from that observed in the SIV-infected RMs with uncontrolled (e.g., high-viral-load) infection $(P<0.02)$.

infections - without expanding unnecessary or potentially deleterious populations or "overstimulating" the regenerative machinery. However, effective application of therapeutic IL-15 in HIV infection will be complicated by several factors. First, even in uninfected RMs, the ability of IL-15 to expand $\mathrm{T}_{\mathrm{EM}}$ cells is limited by "target cell" availability and responsiveness. While initial dosing leads to dramatic increases in $\mathrm{T}_{\mathrm{EM}}$ cell proliferation, this response wanes with continued IL-15 administration at short dosing intervals. This phenomenon might arise from the induction of members of the SOCS gene family that act to shut down IL-15 responsiveness by "feedback" inhibition of JAK/STAT signaling (17). Optimized IL-15 regimens must therefore take into account this refractory period, allowing time for new IL-15-responsive cells to develop from $\mathrm{T}_{\mathrm{CM}}$ cell precursors or for previously responsive cells to regain IL-15 sensitivity.

Second, IL-15's pro-proliferative activity was differentiation hierarchy by inducing memory characteristics on naive cells, conceivably undermining, either by exhaustion or by excessive differentiation, the longevity of this population, its subsequent ability to self-renew, and its ability to manifest a normal program of antigen-induced expansion and differentiation.

Taken together, the available evidence indicates that IL-2, IL-7, and IL-15 have distinct and likely complementary roles in the development and maintenance of the naive, $\mathrm{T}_{\mathrm{CM}}, \mathrm{T}_{\mathrm{EM}}$, and regulatory $\mathrm{T}$ cell compartments, and that they will have significantly different effects when used therapeutically to regenerate these $\mathrm{T}$ cell compartments after pathologic depletion. As IL-15 is uniquely selective for the effector end of the $\mathrm{T}$ cell differentiation spectrum, and as $\mathrm{CD}^{+} \mathrm{T}_{\mathrm{EM}}$ cell populations are selectively depleted in HIV/ SIV infection $(5-7,11)$, IL-15 would appear to represent the most specific therapy to correct the primary deficit engendered by these either absent (CD4 ${ }^{+} \mathrm{T}_{\mathrm{EM}}$ cells) or markedly blunted (CD8 ${ }^{+} \mathrm{T}_{\mathrm{EM}}$ cells) in RMs with uncontrolled SIV replication. This observation is not surprising, given that uncontrolled SIV infection is associated with strikingly high memory $\mathrm{T}$ cell activation, proliferation, and turnover (7). From an analytic standpoint, it is difficult to visualize an IL-15-mediated increase in proliferation when baseline levels are so high. From a mechanistic standpoint, it is highly likely that the high baseline memory $\mathrm{T}$ cell proliferation in infected RMs is secondary to signaling of common $\gamma$ chain cytokines, resulting in induction of the feedback inhibition mechanisms described above. Moreover, the high turnover (e.g., limited survival times) of the highly activated $\mathrm{CD}^{+}$and $\mathrm{CD}^{+}$memory cells in infected animals (7) may prevent the accumulation necessary to visualize an IL-15 effect. Finally, $\mathrm{CD}^{+} \mathrm{T}_{\mathrm{EM}}$ cells are profoundly depleted in typical SIV-infected RMs, leaving very few cells available to respond to therapeutic IL-15. 
A

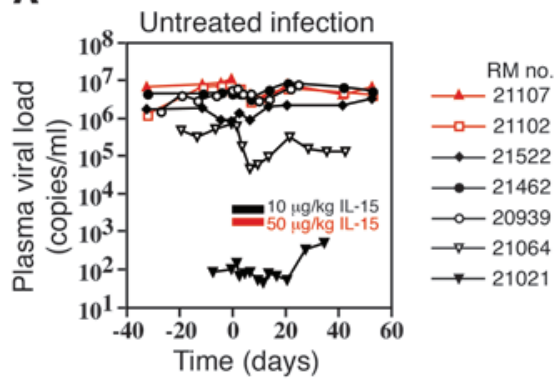

B

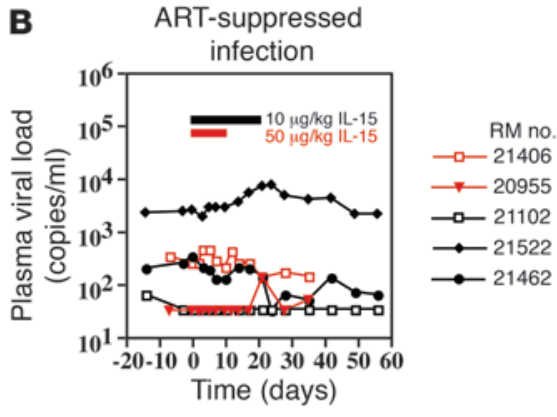

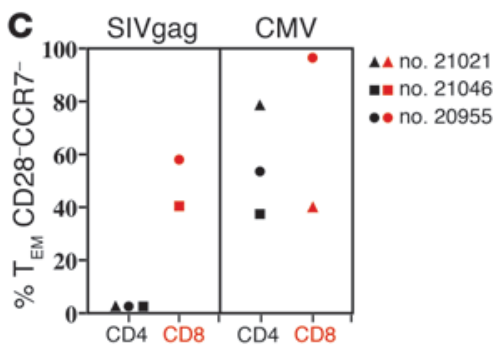

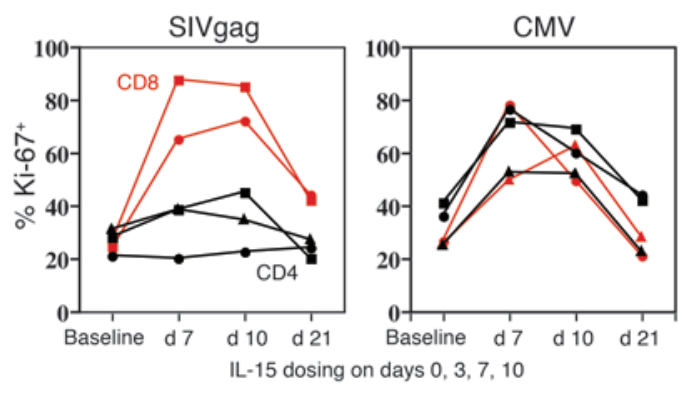

Figure 9

Short-term IL-15 therapy does not increase viral replication in either ART-treated or untreated RMs and influences proliferation of pathogen-specific T cells based on their $T_{E M}$ component. (A and $\left.\mathbf{B}\right)$ Plasma viral loads of untreated (A) or ART-treated (B), SIV-infected RMs are shown before, during, and after IL-15 therapy. (C) Cytokine flow cytometry was used to determine the pre-IL-15-treatment memory phenotype (CD28 versus CCR7) and follow the post-IL-15-treatment proliferative status (Ki-67 expression) of peripheral blood $\mathrm{CD}^{+}$and $\mathrm{CD} 8^{+}$memory $\mathrm{T}$ cells responsive to SIVgag or RhCMV in 3 SIV-infected animals previously shown to have IL-15-responsive total $T_{\text {EM }}$ cell populations (see Figure 8) - the 1 spontaneous controller (no. 21021) given $10 \mu \mathrm{g} / \mathrm{kg}$, and 2 ART-treated RMs (nos. 21046 and 20955) given $50 \mu \mathrm{g} / \mathrm{kg}$. Note that in all $3 \mathrm{RMs}, \mathrm{CMV}$-specific CD4+ T cells included a large fraction of $\mathrm{T}_{\mathrm{EM}}$ cells and showed a marked in vivo proliferative response to IL-15; in contrast, SIVgag-specific CD4 ${ }^{+} \mathrm{T}$ cells included negligible $\mathrm{T}_{\mathrm{EM}}$ cells and little proliferative response to IL-15. Both SIVgag- and RhCMV-specific CD8 ${ }^{+}$T cells (in the 2 of 3 RMs that manifested such responses) included a large $\mathrm{T}_{\mathrm{EM}}$ component and manifested IL-15 responsiveness.

In untreated SIV infection, systemic immune activation stimulates the production of critically needed "new" $\mathrm{CD} 4^{+} \mathrm{T}_{\mathrm{EM}}$ cells, just enough to replace lost cells and maintain minimal levels in effector compartments (7). However, the intensity and/or quality of the activation limits this salutary effect by shortening the survival of these new cells and ultimately undermines the process by damaging precursor populations and the regenerative microenvironments (1). Control of viral replication decreases immune activation (44), presumably arresting the ongoing damage, but also removing some of the impetus for new $\mathrm{T}_{\mathrm{EM}}$ cell production. An appropriate goal of immune replacement therapy in the setting of ART might be to "add back" a sufficient immune stimulation to support maximal $\mathrm{CD} 4^{+} \mathrm{T}_{\mathrm{EM}}$ cell production under conditions that would allow long-term survival of new cells, and not overstimulate the system. Our data suggest that an optimized IL-15 regimen might provide just such a balanced "add-back." We demonstrate that with virologic control by ART, infection-associated immune activation is reduced, circulating $\mathrm{CD} 4^{+} \mathrm{T}_{\mathrm{EM}}$ cell populations reappear, and IL-15 can again be demonstrated to boost both CD4 ${ }^{+}$ and $\mathrm{CD} 8^{+} \mathrm{T}_{\mathrm{EM}}$ and transitional cell proliferation.

In essence, IL-15 restores maximal proliferation among tissuehoming, memory $\mathrm{T}$ cells in virologically suppressed RMs and therefore would be predicted to increase the kinetics and extent of effecand $\mathrm{T}_{\mathrm{CM}}$ precursor populations might limit the efficacy of IL- 15 monotherapy. In this situation, a case might be made for alternating cycles of low-dose IL-7 and IL-15, the former to boost precursor populations in secondary lymphoid tissues, the latter to use these precursor populations to restore tissue $\mathrm{T}_{\mathrm{EM}}$ cell compartments.

In summary, this report documents the ability of IL-15 to regulate the development and maintenance of both $\mathrm{CD}^{+}{ }^{+}$and $\mathrm{CD} 8^{+}$ $\mathrm{T}_{\mathrm{EM}}$ cell populations and points to the potential of IL-15 therapy to promote $\mathrm{CD} 4^{+} \mathrm{T}_{\mathrm{EM}}$ cell reconstitution in HIV infection. This potential could initially be explored in a controlled NHP study quantitatively comparing mucosal $\mathrm{CD} 4^{+} \mathrm{T}$ cell reconstitution, $\mathrm{SIV}^{-}$and opportunistic pathogen-specific $\mathrm{T}$ cell populations, and viral dynamics in SIV-infected RMs treated with ART alone versus ART plus IL-15 therapy. Moreover, these new insights into IL-15 function help clarify the relative roles of IL-2, IL-7, and IL-15 in peripheral $\mathrm{T}$ cell physiology, suggesting that these cytokines complement each other by differential focus on immunoregulation, naive/ $T_{C M}$ cell homeostasis, and $T_{E M}$ cell development, respectively. Although the details of how these and other $\mathrm{T}$ cell regulators interact to maintain a balanced, functioning peripheral immune system remain to be elucidated, these new insights provide a useful paradigm for rational design of immune reconstitution therapy in all relevant settings. 


\section{Methods}

Animals and veterinary procedures. A total of 34 purpose-bred juvenile and adult male RMs (Macaca mulatta) of Indian genetic background and free of cercopithecine herpesvirus 1, D-type simian retrovirus, simian T-lymphotrophic virus type 1 , and SIV infection were used in this study. Nine of these RMs were assessed for IL-15 responsiveness after experimental infection with SIVmac239 (5 ng equivalents given i.v.) (7), including 3 animals studied both before (day 160 postinfection) and after ART (day 357 postinfection, day 49 post-ART), 4 animals studied with untreated infection only (day 160, 454, 497, and 589 postinfection, respectively), and 2 animals studied with ART-suppressed infection only (both at day 809 postinfection, day 195 post-ART). ART consisted of daily s.c. injections of 9-R-(2-phosphono methoxypropyl)adenine (PMPA; tenofovir; $30 \mathrm{mg} / \mathrm{kg}$ ) and $\beta$-2', $3^{\prime}$-dideoxy$3^{\prime}$-thia-5-fluorocytidine (FTC; emtricitabine; $30 \mathrm{mg} / \mathrm{kg}$ ) (35). Plasma SIV RNA was assessed using a real-time RT-PCR assay, as previously described (47). Of the 25 non-SIV-infected RMs, all healthy animals with normal $\mathrm{CD}^{+}$and $\mathrm{CD}^{+} \mathrm{T}$ cell memory compartments, 8 were given cytokines at 1 or more time points; the remaining 17 served as untreated controls for comparative BrdU labeling studies or were used for phenotypic analysis of tissue memory populations. BAL collection and BrdU administration were performed as previously described (7). Intestinal mucosal specimens were obtained via endoscopically guided biopsy of the upper small intestine. All RMs were housed at the Oregon National Primate Research Center in accordance with standards of the Center's Animal Care and Use Committee and the NIH "Guide for the Care and Use of Laboratory Animals" (48). All animal experiments were approved by the Oregon National Primate Research Center's Animal Care and Use Committee.

Immunofluorescent staining and flow cytometric analysis. PBMCs, BAL, and intestinal mucosal cells were prepared for flow cytometric analysis as previously described $(7,11,30)$. Polychromatic (6- to 10-color) flow cytometric analysis was performed on a 3-laser BD LSR II instrument using Pacific Blue, AmCyan, FITC, PE, PE-Texas red, PE-Cy7, peridinin chlorophyl protein-Cy5.5 (True Red), allophycocyanin, allophycocyanin-Cy7, and Alexa 700 as the available fluorescent parameters. Instrument setup and data acquisition procedures were performed as previously described (49). List-mode multiparameter data files were analyzed using the FlowJo software program (version 6.3.1; Tree Star Inc.). Each peripheral blood analysis included lineage-defining markers $(C D 4, C D 8 \alpha$ or $C D 8 \alpha \beta$, and CD3), phenotyping markers (CD28, $\beta_{7}$-integrin, CD95, CCR7, or CCR5), and response markers (Ki-67, anti-BrdU). After gating on $\mathrm{CD} 4^{+}$or $\mathrm{CD}^{+} \mathrm{T}$ cells, the overall memory and naive $T$ cell subsets were delineated based on CD28, $\beta_{7}$-integrin, CCR7, CCR5, and CD95 expression patterns $(30,34)$. Briefly, naive cells constitute a uniform cluster of cells with a CD28 $8^{\text {moderate, }}$ $\beta_{7^{-}}$integrin ${ }^{\text {moderate }}$, CCR7 $7^{\text {moderate }}$, CCR5-, CD95 $5^{\text {low }}$ phenotype, which are clearly distinguishable from the phenotypically diverse memory population that are predominantly $\mathrm{CD} 95^{\text {high }}$ (all $\mathrm{T}_{\mathrm{CM}}$ and most $\mathrm{T}_{\mathrm{EM}}$ ) or, if $\mathrm{CD} 95^{\text {low, }}$, display 1 or more of the following "non-naive" phenotypic features: CD28, CCR7 $^{-}, \mathrm{CCR}^{+}, \beta_{7}$-integrin ${ }^{\text {bright }}$, and $\beta_{7}$-integrin ${ }^{-/ \mathrm{dim}}$. All analyses included CD95 and at least 2 of these other phenotypic markers for memory subset discrimination. Gated memory cells were then separated into CD28 versus
CCR7- or CCR5-defined subsets. As lung lavage T cells are invariably all memory cells (30), assessment of BrdU and Ki-67 expression by these cells was performed directly on gated $\mathrm{CD} 4^{+}$versus $\mathrm{CD}^{+} \mathrm{T}$ cell populations. Cytokine flow cytometry was used to analyze the effect of IL-15 on peripheral blood $\mathrm{T}$ cells responsive to SIVgag peptide mixes (15-mers overlapping by 11 amino acids), whole RhCMV lysates, or a specific RhCMV IE-1 peptide, using concomitant CD69 upregulation and TNF- $\alpha$ production as the specific read-out, as previously described $(30,49)$.

Cytokines and $m A$ s. Cloning, production, and quality control of recombinant rhesus IL-15 (GenBank sequence number U19843) was performed as previously described (31). IL-15 preparations used in this study had bioactivities of between $4 \times 10^{6}$ and $6 \times 10^{6} \mathrm{U} / \mathrm{mg}$ and contained less than 0.3 endotoxin units per microgram IL-15 by Limulus amoebocyte assay. Recombinant human IL-2 (Proleukin) was obtained from Chiron Corp. Monoclonal antibodies L200 (CD4; AmCyan, allophycocyanin-Cy7), SP34-2 (CD3; True Red), SK1 (CD8 $\alpha$; allophycocyanin-Cy7, True Red, PE-Cy7), CD28.2 (CD28; PE, True Red, unconjugated), B56 (Ki-67; FITC, PE), B44 (anti-BrdU; FITC), DX2 (CD95; PE, allophycocyanin, PE-Cy7), 3A9 (CCR5; PE, allophycocyanin), FIB504 ( $\beta_{7}$-integrin; PE, PE-Cy7), FN50 (CD69; PE), 9F10 (CD49d; unconjugated), and MAB11 (anti-TNF- $\alpha$; allophycocyanin) were obtained from BD Biosciences. Monoclonal antibodies 2ST8.5h7 (CD8 $\beta$; PE, PE-Cy7), CD28.2 (PE-Texas red), and streptavidin-PE-Cy7 were obtained from Beckman Coulter. FN18 (CD3) was produced and purified in house and conjugated to Pacific Blue or Alexa 700 using a conjugation kit from Invitrogen Corp. Monoclonal antibody 150503 (anti-CCR7) was purchased as purified Ig from R\&D Systems, conjugated to biotin using a Pierce biotinylation kit, and visualized with streptavidin-Pacific Blue (Invitrogen Corp.).

Statistics. Statistical analysis was conducted with the program StatView (Abacus Concepts Inc.). The significance of differences between pre- and post-treatment values was assessed with a paired 2-tailed Student's $t$ test. Comparisons between different groups of animals (treated versus control; SIV-infected versus uninfected or ART-treated infected) or different treatment regimens (IL-15 versus IL-2) were made using an unpaired, 2-tailed Student's $t$ test. $P$ values less than 0.05 were considered significant.

\section{Acknowledgments}

This work was supported by NIH grants RO AI054292, P51 RR00163, U42 RR016025, U24 RR018107, and R24 RR16988 and by National Cancer Institute funds under contract NO1-CO124000. The authors would like to thank J. Zhao for the preparation of rMamu IL-15, and M. Miller at Gilead Sciences Inc. for provision of PMPA and FTC.

Received for publication December 2, 2005, and accepted in revised form March 7, 2006.

Address correspondence to: Louis J. Picker, Vaccine and Gene Therapy Institute, Oregon Health \& Science University-West Campus, 505 NW 185th Avenue, Beaverton, Oregon 97006, USA. Phone: (503) 418-2720; Fax: (503) 418-2719; E-mail: pickerl@ohsu.edu.
1. Douek, D.C., Picker, L.J., and Koup, R.A. 2003. T cell dynamics in HIV-1 infection. Annu. Rev. Immunol. 21:265-304.

2. Veazey, R., and Lackner, A. 2003. The mucosal immune system and HIV-1 infection. AIDS Rev. 5:245-252.

3. Mehandru, S., Tenner-Racz, K., Racz, P., and Markowitz, M. 2005. The gastrointestinal tract is critical to the pathogenesis of acute HIV-1 infection. J. Allergy Clin. Immunol. 116:419-422.

4. Sallusto, F., Geginat, J., and Lanzavecchia, A. 2004. Central memory and effector memory $\mathrm{T}$ cell sub- sets: function, generation, and maintenance. Annu. Rev. Immunol. 22:745-763.

5. Brenchley, J.M., et al. 2004. CD4+ T cell depletion during all stages of HIV disease occurs predominantly in the gastrointestinal tract. J. Exp. Med. 200:749-759.

6. Mehandru, S., et al. 2004. Primary HIV-1 infection is associated with preferential depletion of CD $4+T$ lymphocytes from effector sites in the gastrointestinal tract. J. Exp. Med. 200:761-770.

7. Picker, L.J., et al. 2004. Insufficient production and tissue delivery of CD4+ memory T cells in rapidly progressive simian immunodeficiency virus infection. J. Exp. Med. 200:1299-1314.

8. Mattapallil, J.J., et al. 2005. Massive infection and loss of memory CD4+ $\mathrm{T}$ cells in multiple tissues during acute SIV infection. Nature. 434:1093-1097.

9. Veazey, R.S., et al. 1998. Gastrointestinal tract as a major site of CD4+ T cell depletion and viral replication in SIV infection. Science. 280:427-432.

10. Kewenig, S., et al. 1999. Rapid mucosal CD4(+) T-cell depletion and enteropathy in simian immunodeficiency virus-infected rhesus macaques. Gastroenterology. 116:1115-1123. 
11. Veazey, R.S., et al. 2000. Dynamics of CCR5 expression by CD4(+) T cells in lymphoid tissues during simian immunodeficiency virus infection. J. Virol. 74:11001-11007.

12. Miao, Y.M., et al. 2002. Elevated mucosal addressin cell adhesion molecule- 1 expression in acquired immunodeficiency syndrome is maintained during antiretroviral therapy by intestinal pathogens and coincides with increased duodenal CD4 T cell densities. J. Infect. Dis. 185:1043-1050.

13. Krzysiek, R., et al. 2001. Preferential and persistent depletion of CCR5+ T-helper lymphocytes with nonlymphoid homing potential despite early treatment of primary HIV infection. Blood. 98:3169-3171.

14. Guadalupe, M., et al. 2003. Severe CD4+ T-cell depletion in gut lymphoid tissue during primary human immunodeficiency virus type 1 infection and substantial delay in restoration following highly active antiretroviral therapy. J. Virol. 77:11708-11717.

15. Surh, C.D., and Sprent, J. 2005. Regulation of mature T cell homeostasis. Semin. Immunol. 17:183-191.

16. Gaffen, S.L., and Liu, K.D. 2004. Overview of interleukin-2 function, production and clinical applications. Cytokine. 28:109-123.

17. Kovanen, P.E., and Leonard, W.J. 2004. Cytokines and immunodeficiency diseases: critical roles of the gamma(c)-dependent cytokines interleukins 2 , $4,7,9,15$, and 21 , and their signaling pathways. Immunol. Rev. 202:67-83.

18. Alpdogan, O., and van den Brink, M.R. 2005. IL-7 and IL-15: therapeutic cytokines for immunodeficiency. Trends Immunol. 26:56-64.

19. Fry, T.J., and Mackall, C.L. 2002. Interleukin-7: from bench to clinic. Blood. 99:3892-3904.

20. Malek, T.R., and Bayer, A.L. 2004. Tolerance, not immunity, crucially depends on IL-2. Nat. Rev. Immunol. 4:665-674.

21. Moniuszko, M., et al. 2004. Recombinant interleukin-7 induces proliferation of naive macaque CD4+ and CD8+ T cells in vivo. J. Virol. 78:9740-9749.

22. Fry, T.J., et al. 2003. IL-7 therapy dramatically alters peripheral T-cell homeostasis in normal and SIV-infected nonhuman primates. Blood. 101:2294-2299.

23. Prlic, M., Lefrancois, L., and Jameson, S.C. 2002. Multiple choices: regulation of memory CD8 T cell generation and homeostasis by interleukin (IL)-7 and IL-15. J. Exp. Med. 195:F49-F52.

24. Ahmad, A., et al. 2005. IL-15 and HIV infection: lessons for immunotherapy and vaccination. Curr. HIV Res. 3:261-270.

25. Mueller, Y.M., et al. 2003. IL-15 enhances survival and function of HIV-specific CD8+ T cells. Blood. 101:1024-1029.

26. Zhang, X., Sun, S., Hwang, I., Tough, D.F., and Sprent, J. 1998. Potent and selective stimulation of memory-phenotype CD8+ T cells in vivo by IL- 15 . Immunity. 8:591-599.

27. Lodolce, J.P., Burkett, P.R., Boone, D.L., Chien, M., and Ma, A. 2001. T cell-independent interleukin 15Ralpha signals are required for bystander proliferation. J. Exp. Med. 194:1187-1194.

28. Tan, J.T., et al. 2002. Interleukin (IL)-15 and IL-7 jointly regulate homeostatic proliferation of memory phenotype CD8+ cells but are not required for memory phenotype CD4+ cells. J. Exp. Med. 195:1523-1532.

29. Mueller, Y.M., et al. 2005. Interleukin-15 increases effector memory CD8+ T cells and NK cells in simian immunodeficiency virus-infected macaques. J. Virol. 79:4877-4885.

30. Pitcher, C.J., et al. 2002. Development and homeostasis of $\mathrm{T}$ cell memory in rhesus macaque. J. Immunol. 168:29-43.

31. Villinger, F., et al. 2004. IL-15 is superior to IL-2 in the generation of long-lived antigen specific memory CD4 and CD8 T cells in rhesus macaques. Vaccine. 22:3510-3521.

32. Unutmaz, D., et al. 2000. The primate lentiviral receptor Bonzo/STRL33 is coordinately regulated with CCR5 and its expression pattern is conserved between human and mouse. J. Immunol. 165:3284-3292.

33. Geginat, J., Sallusto, F., and Lanzavecchia, A. 2001. Cytokine-driven proliferation and differentiation of human naive, central memory, and effector memory CD4(+) T cells. J. Exp. Med. 194:1711-1719.

34. Sun, Y., et al. 2005. Dysfunction of simian immunodeficiency virus/simian human immunodeficiency virus-induced IL-2 expression by central memory CD4+ T lymphocytes. J. Immunol. 174:4753-4760.

35. Shen, A., et al. 2003. Resting CD4+ T lymphocytes but not thymocytes provide a latent viral reservoir in a simian immunodeficiency virus-Macaca nemestrina model of human immunodeficiency virus type 1 -infected patients on highly active antiretroviral therapy. J. Virol. 77:4938-4949.

36. Kovacs, J.A., et al. 2005. Induction of prolonged survival of $\mathrm{CD}^{+} \mathrm{T}$ lymphocytes by intermittent IL-2 therapy in HIV-infected patients. J. Clin. Invest.
115:2139-2148. doi:10.1172/JCI23196.

37. Farel, C.E., et al. 2004. Induction and maintenance therapy with intermittent interleukin-2 in HIV-1 infection. Blood. 103:3282-3286.

38. Levy, Y., et al. 2003. Effects of interleukin-2 therapy combined with highly active antiretroviral therapy on immune restoration in HIV-1 infection: a randomized controlled trial. AIDS. 17:343-351.

39. Sereti, I., et al. 2005. In vivo expansion of $\mathrm{CD} 4{ }^{+} \mathrm{CD} 45 \mathrm{RO}-\mathrm{CD} 25^{+} \mathrm{T}$ cells expressing foxP 3 in IL-2-treated HIV-infected patients. J. Clin. Invest. 115:1839-1847. doi:10.1172/JCI24307.

40. Nugeyre, M.T., et al. 2003. IL-7 stimulates T cell renewal without increasing viral replication in simian immunodeficiency virus-infected macaques. J. Immunol. 171:4447-4453.

41. Storek, J., et al. 2003. Interleukin-7 improves CD4 T-cell reconstitution after autologous CD34 cell transplantation in monkeys. Blood. 101:4209-4218.

42. van Leeuwen, E.M., et al. 2005. IL-7 receptor alpha chain expression distinguishes functional subsets of virus-specific human CD8+ T cells. Blood. 106:2091-2098.

43. Paiardini, M., et al. 2005. Loss of CD127 expression defines an expansion of effector CD8+ T cells in HIVinfected individuals. J. Immunol. 174:2900-2909.

44. Lempicki, R.A., et al. 2000. Impact of HIV-1 infection and highly active antiretroviral therapy on the kinetics of CD4+ and CD8+ T cell turnover in HIV-infected patients. Proc. Natl. Acad. Sci. U. S. A. 97:13778-13783.

45. Mastroianni, C.M., d'Ettorre, G., Forcina, G., and Vullo, V. 2004. Teaching tired T cells to fight HIV: time to test IL-15 for immunotherapy? Trends Immunol. 25:121-125.

46. McInnes, I.B., and Gracie, J.A. 2004. Interleukin-15: a new cytokine target for the treatment of inflammatory diseases. Curr. Opin. Pharmacol. 4:392-397.

47. Cline, A.N., Bess, J.W., Piatak, M., Jr., and Lifson, J.D. 2005. Highly sensitive SIV plasma viral load assay: practical considerations, realistic performance expectations, and application to reverse engineering of vaccines for AIDS. J. Med. Primatol. 34:303-312.

48. Institute for Laboratory Animal Research. 1996. Guide for the care and use of laboratory animals. National Academic Press. Washington, DC, USA. 125 pp.

49. Walker, J.M., Maecker, H.T., Maino, V.C., and Picker, L.J. 2004. Multicolor flow cytometric analysis in SIV-infected rhesus macaque. Methods Cell Biol. 75:535-557. 